J. Lake Sci. (湖泊科学), 2013, 25(1): 108-114

http: //www.jlakes.org. E-mail : jlakes@niglas. ac.cn

(c) 2013 by Journal of Lake Sciences

\title{
贵州红枫湖越冬藻类的空间分布与实验室复苏实验"
}

\author{
王敬富 ${ }^{1,2}$, 陈敬安 ${ }^{1 * *}$, 李秋华 $^{3}$, 夏品华 $^{3}$, 曾 軟 $^{1,2}$, 杨永琼 $^{1,2}$, 杨海全 $^{1,2}$ \\ (1: 中国科学院地球化学研究所, 环境地球化学国家重点实验室, 贵阳 550002) \\ (2: 中国科学院大学, 北京 100049) \\ ( 3 : 贵州师范大学贵州省山地环境信息系统和生态环境保护重点实验室,贵阳 550001)
}

摘 要: 本文选取贵州省红枫湖这一典型的亚深水型湖泊作为研究对象, 在 8 个代表性湖区开展了为期一年的表层水体 藻类浮游植物分布的月定量监测, 并在 4 个采样点采集新鲜沉积物进行了越冬藻类赋存与复苏模拟实验研究. 研究表明, 红枫湖表层水体藻类种群密度蓝藻 $\gg$ 绿藻 $>$ 硅藻 $>$ 甲藻, 蓝藻为优势门类, 水体藻类种群密度秋季初期最高, 其次是春 季初期和夏季, 具有明显的季节性演化特征. 水体中越冬藻类以蓝藻为主, 其次是硅藻和绿藻, 水深对水体中藻类的种群 密度及组成没有显著影响. 沉积物中越冬藻类以硅藻为主, 基本不含蓝藻. 模拟实验表明, 水体中的光照条件对藻类的复 苏和生长有重要影响, 温度和沉积物中藻类的种群密度与组成同样影响藻类的复苏.

关键词: 红枫湖;藻类;越冬;复苏;光照;空间分布

\section{Spatial distribution and recruitment simulation test of over-winter algae in Lake Hongfeng, Guizhou}

WANG Jingfu ${ }^{1,2}$, CHEN Jing'an ${ }^{1}$, LI Qiuhua ${ }^{3}$, XIA Pinhua ${ }^{3}$, ZENG Yan ${ }^{1,2}$, YANG Yongqiong ${ }^{1,2} \&$ YANG Haiquan ${ }^{1,2}$

(1: State Key Laboratory of Environmental Geochemistry, Institute of Geochemistry, Chinese Academy of Sciences, Guiyang 550002, P. R. China)

(2: University of Chinese Academy of Sciences, Beijing 100049, P. R. China)

(3: Guizhou Key Laboratory for Mountainous Environmental Information and Ecological Protection, Guizhou Normal University, Guiyang 550001, P. R. China)

Abstract: In order to investigate the spatial variations of the over-winter algae in different areas of Lake Hongfeng, sediment and water samples were collected monthly at 8 sites over a period of 1 year. Simulation test of dormancy algae recruitment from sediments collected form 4 sites were carried out. The results showed that cyanobacteria were the dominant species in surface water, and the population density of the cyanobacteria was significantly higher than the green algae, diatoms and dinoflagellates. Algal population density evolved seasonally, which was the highest in early autumn and followed by the early spring and summer. Cyanobacteria dominated in over-winter algae in water, followed by diatoms and green algae. The water depth did not affect significantly the population density and composition of the algae in water. Differing from in water, over-winter algae in sediments were mostly diatoms, and only small amount of cyanobacteria were found. Simulation experiments showed that light intensity had a major impact on the algae recruitment, which was also affected by water temperature and sediment algae population density.

Keywords: Lake Hongfeng; algae; over-winter; recruitment; light; spatial distribution

藻类水华是与湖泊富营养化相伴随的一个普遍现象 ${ }^{[1]}$, 往往导致湖泊水质下降及一系列严重的水环境 问题 ${ }^{[2]}$. 很多藻类可以在不适宜生长的条件下附着在湖泊底泥表面 ${ }^{[3]}$, 产生被称为休眠孢子 (Akinete) 的特

* 国家科技支撑计划项目 (2011BAC02B0201) 和贵阳市重大科技专项计划项目联合资助. 2012-03-26 收稿;201207-17 收修改稿. 王敬富,男,1983 年生,博士研究生;E-mail : geoolivine@ 126. com.

** 通信作者;E-mail : chenjingan@ vip. skleg. cn. 
殊生殖细胞 ${ }^{[4-5]}$. 水华蓝藻微囊藻虽然不能形成特殊形态的休眠细胞, 但秋冬季也会在底泥中聚集, 以度过 一段不利于生长的时期 ${ }^{[6-8]}$. Preston 等用 $\mathrm{N}$ 稳定同位素示踪的方法表明,夏季水体中的微囊藻群体来自于越 冬底泥中的微囊藻群体 ${ }^{[9]}$. 这种位于沉积物中的蓝藻群体聚集可能为次年蓝藻的生长提供种源, 甚至可能 成为蓝藻大量增长的重要来源 ${ }^{[10-11]}$. 孔繁翔等 ${ }^{[2]}$ 和阎荣等 ${ }^{[12]}$ 提出假设, 将蓝藻水华的形成分为相互区别而 又连续的 4 个过程, 即下沉和越冬 (休眠)、复苏、生物量增加、上浮聚集并形成水华, 并指出太湖之所以在较 短时间内形成水华, 与底泥中的蓝藻复苏 (Recruitment) 及其上升密切相关.

目前关于沉积物越冬藻类的研究集中在蓝藻的垂直迁移以及复苏对于次年夏季蓝藻水华构成的影响 上 $^{[13-15]}$. 在浅水湖泊中, 沉积物表面蓝藻的上浮主要是由风力引起的水力扰动形成的被动过程 ${ }^{[16]}$, 而且风力 扰动会导致大量的营养盐从沉积物中释放出来, 大大增加了水体中藻类可利用的营养盐含量 ${ }^{[17-18]}$. 深水湖 泊中, 水文、气象等条件可以通过影响湖泊水体的分层、混合 ${ }^{[19]}$ 以及光照 ${ }^{[20]}$ 、营养盐的可利用性等直接或间 接地影响蓝藻种群的细胞密度、种群组成、垂直分布、生命周期等. Hansson 研究表明, 在深水湖泊中微囊藻 的复苏大部分发生在浅水区域 ${ }^{[21]}$. Tsujimura 等对日本 Biwa 湖的研究发现, 深水湖湾的底泥中群体微囊藻的 数量多于浅水区, 且深水区没有发现群体微囊藻的季节变动 ${ }^{[11]}$. 在低温和低光照的耦合环境中, 越冬期微囊 藻依靠消耗前期积累的糖原和 PHB 以维持其代谢活动 ${ }^{[22]}$. 目前, 对深水-亚深水型湖泊藻类复苏和蓝藻水 华形成过程的研究远落后于浅水湖泊, 需加强系统性研究. 本文选取贵州省红枫湖这一典型的季节性分层 的亚深水型湖泊开展越冬藻类的研究, 旨在深化对亚深水型湖泊越冬藻类的空间分布规律以及复苏机制和 控制因素的认识.

\section{1 材料与方法}

\section{1 采样点选择}

红枫湖是乌江支流猫跳河梯级开发的人工湖, 属峡谷断陷盆地的河道型水库 (图 1), 也是贵阳城市供水 的重要水源地, 水面面积 $57.2 \mathrm{~km}^{2}$, 平均水深 $10.5 \mathrm{~m}$. 低纬度和 高海拔,加之急剧变化的区域气候对水体季节性分层的湖泊环 境系统带来突发性影响 ${ }^{[23-24]}$. 近年来, 红枫湖突发性水质恶化 事件时有发生, 局部藻类水华严重, 富营养化问题日益突出. 本 次共计布设 9 个采样点 (图 1$)$, 分别为三岔河 $\left(1^{\#}\right)$ 、大岗 $\left(2^{\#}\right)$ 、 南湖中部 $\left(3^{\#}\right) 、$ 后五 $\left(4^{\#}\right)$ 、白岩 $\left(5^{\#}\right)$ 、大坝 $\left(6^{\#}\right) 、 1256$ 岛 $\left(7^{\#}\right)$ 、 腰洞 $\left(8^{\#}\right)$ 和右二湖湾 $\left(9^{\#}\right)$.

\section{2 采样方法与时间}

1.2 .1 水体藻类 2010 年 $1-12$ 月, 每月中旬在 $1^{\#} \sim 8^{\#}$ 点用有 机玻璃采水器定量采集 $1 \mathrm{~L}$ 水样, 表层水样采集深度为水面下 $0.5 \mathrm{~m}$ 处, 底层水样采集深度为沉积物一水界面以上约 $1 \mathrm{~m}$ 处, 加 人 $1.5 \%$ 鲁哥试剂后室内静置 $24 \sim 48 \mathrm{~h}$, 用虹吸法将上清液吸 去, 将浓缩液定容至 $30 \mathrm{ml}$, 用 $0.1 \mathrm{ml}$ 计数框进行显微镜镜检, 对 各采样点的藻类组成和数量进行定量研究. 同时, 利用 YSI 水质 监测仪记录表层水体温度.

1.2 .2 沉积物藻类 2011 年 11 月, 使用抓斗式采泥器在 $3^{\#} 、 4^{\#}$ 、 $6^{\#}$ 和 $9^{\#}$ 点采集表层沉积物, 称取 $100 \mathrm{~g}$ 新鲜泥样用 $0.2 \mathrm{~mm}$ 篮子 初滤后, 用 $25^{\#}$ 浮游植物网过滤, 收集浮游植物网中的残留物, 用蒸馏水冲洗 4 6 次, 加人鲁哥试剂固定, 留待镜检. 同期采集 表层 $(0.5 \mathrm{~m})$ 和底层水体 (距底泥约 $1 \mathrm{~m}$ ) 进行藻类定量研究.

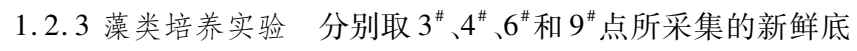
泥样品 $500 \mathrm{~g}$, 置于 $2.5 \mathrm{~L}$ 广口瓶内, 加人 $2 \mathrm{~L} \mathrm{BG}-11$ 培养基进行 连续培养. 实验设温度和光强两种处理, 培养温度: 15、20 和

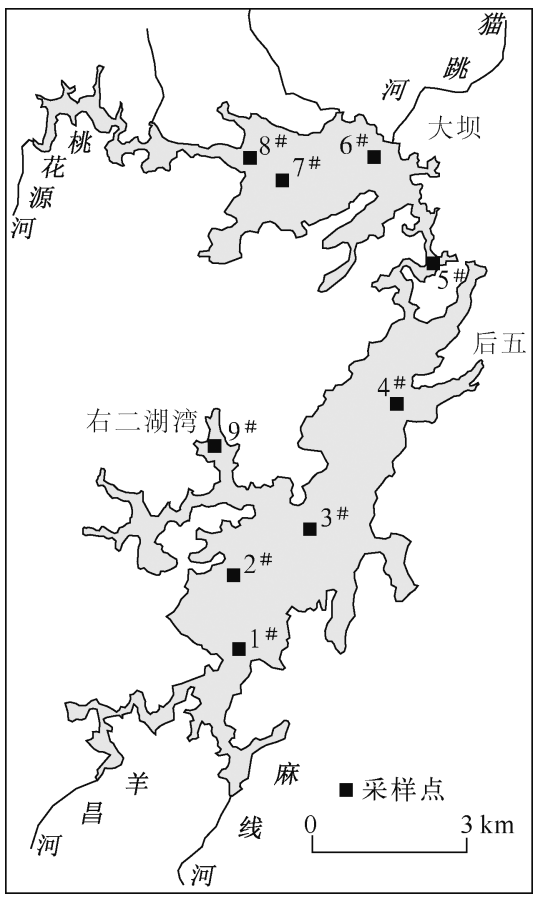

图 1 红枫湖采样点位置

Fig. 1 Location of sampling sites in Lake Hongfeng 
$25^{\circ} \mathrm{C}$, 连续光照, 光照强度 $30 \mu /\left(\mathrm{Em}^{2} \cdot \mathrm{s}\right)$; 培养温度为 $15 、 20$ 和 $25^{\circ} \mathrm{C}$, 黑暗培养. 每个温度停留时间为 $7 \mathrm{~d}$.

\section{2 结果与分析}

\section{1 红枫湖水体藻类的季节变化特征}

红枫湖地处亚热带湿润性季风气候区, 冷暖气流交替强烈, 高原季风气候明显. 2010 年红枫湖表层水体 的平均温度在 $9.7 \sim 28.1{ }^{\circ} \mathrm{C}$ 之间, 冬季 (12、1 和 2 月) 水温在 $9.7 \sim 12.6^{\circ} \mathrm{C}$ 之间, 为全年温度最低的时期. 夏 季(6、7 和 8 月) 水温最高, 在 $21.3 \sim 28.1^{\circ} \mathrm{C}$ 之间. 秋季水温均值为 $20.3^{\circ} \mathrm{C}$, 略高于春季 $\left(17.4^{\circ} \mathrm{C}\right)$. 红枫湖水 温的季节变化对湖泊藻类的演替产生着重要影响.

红枫湖水体藻类具有明显的季节性演化的特征, 秋季初期藻类种群密度最大, 其次是春季初期和夏季, 这与太湖等浅水湖泊藻类复苏及暴发的演化特征有所不同 ${ }^{[25-26]}$. 红枫湖表层水体藻类种群密度为蓝藻》绿 藻 > 硅藻 >甲藻, 蓝藻为红枫湖优势门类. 2010 年 2 月, 蓝藻、绿藻以及甲藻数量均出现峰值, 这一时期湖区 天气转晴, 充足的光照条件为藻类的复苏提供了有利条件. 夏季被认为是蓝藻水华最容易形成和暴发的时 期 $^{[2]}$, 但是红枫湖蓝藻种群密度在夏季为全年最低值. 2010 年 7 月硅藻种群密度显著增加, 绿藻和甲藻种群 密度也有不同程度的增长, 不同藻类在相同光照和营养盐等条件下竞争生存空间, 显然蓝藻在夏季竞争中 处于劣势, 种群密度显著降低(图 2).
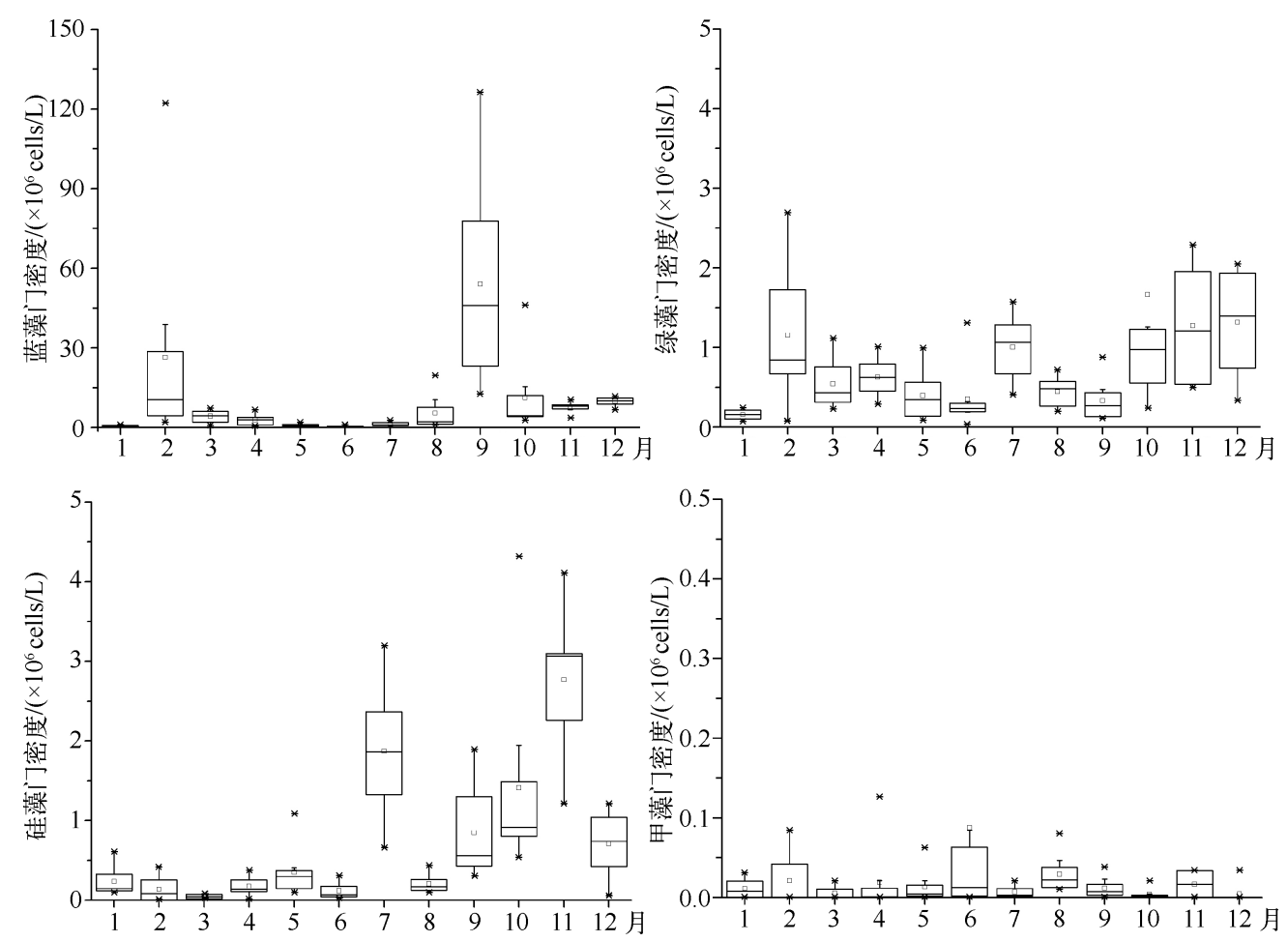

图 2 红枫湖表层水体藻类的年际变化

Fig. 2 Annual variations of algae in surface water in Lake Hongfeng

2010 年 9 月, 红枫湖表层水体蓝澡种群密度剧增至 $54.2 \times 10^{6}$ cells $/ \mathrm{L}$, 占藻类总量的 $97.8 \%$, 成为绝对 优势种属. 同期, 硅藻种群密度与前一个月相比也有一定程度的增长. 藻类种群密度之所以在秋季初期出现 大幅度的变化, 与红枫湖水体季节性分层结构的演化密切相关. 按照 Lewis 基于纬度 (进行了海拔校正) 和水 深的湖泊分类方案 ${ }^{[27]}$, 红枫湖属于暖单次混合型-暖多次混合型湖泊. 湖泊水体的季节性分层历经发生、发 展和消亡等周期性演化阶段, 秋季初期骤然变化的气候引发水体热分层消亡, 造成湖泊水体的垂向对流混 合, 导致大量的营养盐从沉积物中释放出来, 增加了水体中藻类可利用的营养盐含量 ${ }^{[17-18]}$. 同时, 沉降到湖 
底的藻类借助水体交换上浮到湖泊表层, 在温度、光照和营养盐条件的配合下大量生长. 从藻类种群看, 夏 季蓝藻种群密度呈现为全年的低值, 而在季节性分层消亡时期, 其种群密度骤然增加, 数量远远超过硅藻和 绿藻, 一跃变为优势种. 底层浮游藻类和表层沉积物中赋存的藻类在秋季被水体对流交换至表层水体后为 表层水体藻类的大量生长提供了基础, 其中蓝藻生长的温度阈值 $\left(12.5^{\circ} \mathrm{C}\right)$ 虽略高于绿藻和硅藻 $\left(9^{\circ} \mathrm{C}\right)$, 但蓝 藻在恢复活性后的比生长速率最高 ${ }^{[28]}$. 冬季较低的气温对藻类生长并不十分有利, 但是秋初湖泊分层混合 增加了水体中藻类可利用营养盐的含量, 因此, 蓝藻、绿藻和硅藻等种群密度在冬季长期维持在较高的 水平.

\section{2 红枫湖越冬藻类在水体中的分布特征}

红枫湖水体中的越冬藻类以蓝藻为主, 其次是硅藻和绿藻, 甲藻和金藻等数量较少 (图 3). 冬季藻类在 水体中的分布存在空间差异. 从水平分布看,不同湖区藻类的种群密度和组成显著不同,其中右二湖湾藻类 种群密度最大, 其次是南湖中部、后五和大坝湖区. 藻类种群密度沿水流方向呈现由高到低的分布特征, 揭 示了南湖人湖河流是红枫湖最重要的污染物来源, 其水体所富含的氮、磷为湖泊藻类的生长提供了重要营 养基础.

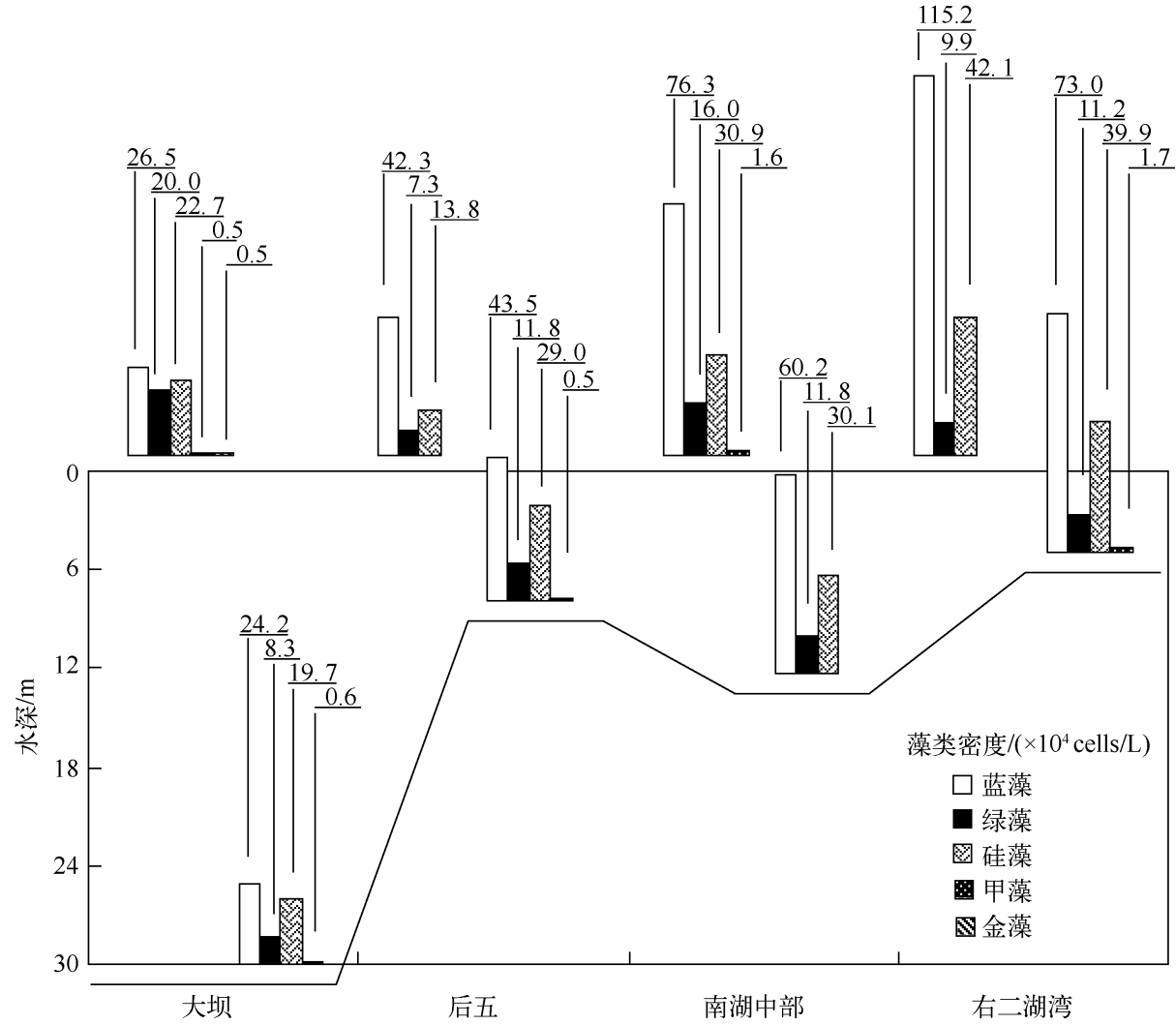

图 3 红枫湖冬季 4 个湖区表层和底层水体中藻类的分布

Fig. 3 Distribution of algae in surface and bottom water in four lake areas, Lake Hongfeng

从垂向分布看,红枫湖的水深 $(6 \sim 30 \mathrm{~m})$ 对水体中藻类的种群密度及组成没有显著影响,相同湖区表层 和底层水体中的藻类种群密度和组成相近. 藻类在垂向上的均匀分布是红枫湖水体秋初时期分层混合所 致, 强烈的垂向对流造成湖泊水体温度梯度消失、溶解氧降低、电导率升高 ${ }^{[19]}$, 与此同时, 藻类等浮游植物在 扰动条件下被动均匀分布在水体中,种群密度在一段较长的时间内维持相对稳定的状态. 但是, 湖泊水体季 节性分层结构的稳定性与水深、气象、水文条件以及湖泊形态等多种因素有关 ${ }^{[27]}$. 红枫湖为亚深水型湖泊, 其季节性分层的周期性演化影响着藻类浮游植物的生命过程和空间分布. 


\section{3 红枫湖越冬藻类在沉积物中的分布特征}

孔繁翔等 ${ }^{[2]}$ 和阎荣等 ${ }^{[12]}$ 提出蓝藻水华发生的四阶段论, 即下沉和越冬 (休眠)、复苏、生物量增加、上浮 聚集并形成水华, 指出沉积物是藻类越冬的重要场所, 水华在短期内形成与底泥中的蓝藻复苏及其上升密 切相关. 与水柱中不同, 红枫湖沉积物中的越冬藻类以绿藻和硅藻为主, 蓝藻数量较少, 底泥环境与水柱环 境的差异导致了藻类种群分布的差异. 与浅水湖泊相比, 红枫湖沉积物一水界面附近光强更低, 在沉积物一水 界面附近低温黑暗的环境条件下, 越冬藻类处于衰亡和休眠状态, 生命代谢活动基本停止. 红枫湖 4 个监测 点表层沉积物均含有一定数量的藻类浮游植物, 绿藻中的单角盘星藻具孔变种是沉积物中种群密度最大的 越冬藻类, 其次是硅藻中的肘状针杆藻和脆杆藻, 蓝藻种类有假鱼腥藻和湖丝藻两种, 种群密度较小 (表1).

表 1 冬季红枫湖表层沉积物中的藻类组成

Tab. 1 Algae composition of surface sediments in winter at Lake Hongfeng

\begin{tabular}{|c|c|c|c|c|}
\hline 种类 & 大坝 & 后五 & 南湖中部 & 右二湖湾 \\
\hline \multicolumn{5}{|l|}{ 蓝藻 } \\
\hline 假鱼腥藻( Pseudanabaena limnetica) & & & & + \\
\hline 湖丝藻 ( Limnthriox sp. ) & + & & + & \\
\hline \multicolumn{5}{|l|}{ 绿藻 } \\
\hline $\begin{array}{l}\text { 单角盘星藻具孔变种 (Pediastrum simplex var. duodenarium) } \\
\text { 多棘鼓藻(Xanthidium sp.) }\end{array}$ & $\begin{array}{l}++ \\
+\end{array}$ & $\begin{array}{l}++ \\
+\end{array}$ & +++ & +++ \\
\hline \multicolumn{5}{|l|}{ 硅藻 } \\
\hline 小环藻 ( Cyclotella sp. ) & + & + & + & + \\
\hline 肘状针杆藻 (Synedra ulna) & +++ & ++ & + & + \\
\hline 颗粒直链藻 (Melosira granulata) & ++ & + & + & + \\
\hline 颗粒直链藻最窄变种 (Melosira granulata var. angustissima mull) & + & + & & \\
\hline 颗粒直链藻最窄变种 (Melosira granulata var. angustissima mull) & + & + & & \\
\hline 湖沼圆笁藻 (Coscinodiscus lacustris) & + & + & & \\
\hline 双眉藻( Amphora sp. ) & & & & + \\
\hline 羽纹藻 ( Pinnularia sp. ) & & & + & \\
\hline 脆杆藻 ( Fragilaria sp. ) & ++ & +++ & + & \\
\hline 菱形藻 ( Nitzschia sp. ) & & + & + & + \\
\hline
\end{tabular}

+ 表示存在 $;++$ 表示数量较多; ++ + 表示优势种属.

从空间分布来讲,红枫湖沉积物越冬藻类种群密度与组成存在空间差异, 大坝湖区沉积物越冬藻类的 种群密度为 $46.5 \times 10^{4}$ cells $/ \mathrm{g}$, 其中硅藻中的肘状针杆藻种群密度为 $21.8 \times 10^{4} \mathrm{cells} / \mathrm{g}$, 绿藻中的单角盘星藻 具孔变种种群密度为 $11.1 \times 10^{4}$ cells $/ \mathrm{g}$, 均明显高于其他三个湖区. 后五、南湖中部和右二湖湾沉积物越冬藻 类的种群密度分别为 $6.0 \times 10^{4} 、 3.8 \times 10^{4}$ 和 $1.0 \times 10^{4} \mathrm{cells} / \mathrm{g}$. 藻类种群密度在沉积物中的分布与沉积物污染 程度有关 ${ }^{[2]}$, 红枫湖底泥有机碳、总磷和总氮的平均含量分别为 $3.20 \% 、 0.12 \%$ 和 $0.31 \%$, 污染程度严重的 大坝和后五湖区三者平均含量分别超过了 $5.00 \% 、 0.25 \%$ 和 $0.50 \%{ }^{[24]}$, 同时两湖区的藻类种群密度也 最大.

越冬藻类在沉积物中的分布受水柱中藻类分布的影响. 冬季, 水柱中的藻类在活性降低后沉降到沉积 物表面, 是沉积物越冬藻类的主要来源. 同时, 水体中的氮、磷营养盐通过颗粒吸附沉降至沉积物表层, 经过 矿化等早期成岩作用在沉积物中累积, 水体和沉积物的营养水平共同影响着藻类的生存环境. 对深水湖泊 而言, 水深同样影响沉积物中越冬藻类的种群密度. 与浅水湖泊相比, 红枫湖沉积物一水界面光照强度低, 底 层水体季节性缺氧 ${ }^{[19]}$, 从而对藻类光合作用活性以及死亡后藻类的腐化分解产生影响. 从藻类组成来看, 沉 积物越冬藻类的种类明显少于同期水柱中的藻类, 仅有部分具有耐低温的生理学特征的硅藻以及绿藻门的 一些种在红枫湖沉积物越冬藻类中种群密度比较高.

\section{4 温度和光照对藻类复苏的影响}

沉积物越冬藻类的复苏为水柱中藻类的生长提供种源 ${ }^{[13-15,29]}$. 多数湖泊中蓝藻的复苏均表明底泥提供 
的蓝藻只占水体中最大生物量的 $0.05 \% \sim 5 \%{ }^{[15,30]}$. 即使如此, 模型研究表明如果忽略沉积物越冬蓝藻的复 苏, 夏季的水华会减少 $50 \%$ 的生物量 ${ }^{[31]}$. 由此可见, 沉积物中越冬藻类的复苏对于春季藻类的生长和暴发 起到关键作用.

模拟实验表明,水体中的光照条件会对藻类生长产生重要的影响. 在温度和营养盐浓度等均相同的情 况下, 大坝和后五沉积物黑暗条件培养出的藻类种群密度均远远低于光照条件培养出的藻类种群密度 (图 4). 以大坝沉积物为例, 在 $15^{\circ} \mathrm{C}$ 、光照条件下培养出的藻类种群密度为 $113.6 \times 10^{4}$ cells $/ \mathrm{L}, 15^{\circ} \mathrm{C}$ 、黑暗条 件培养出的藻类种群密度仅为 $16.2 \times 10^{4} \mathrm{cells} / \mathrm{L}$.
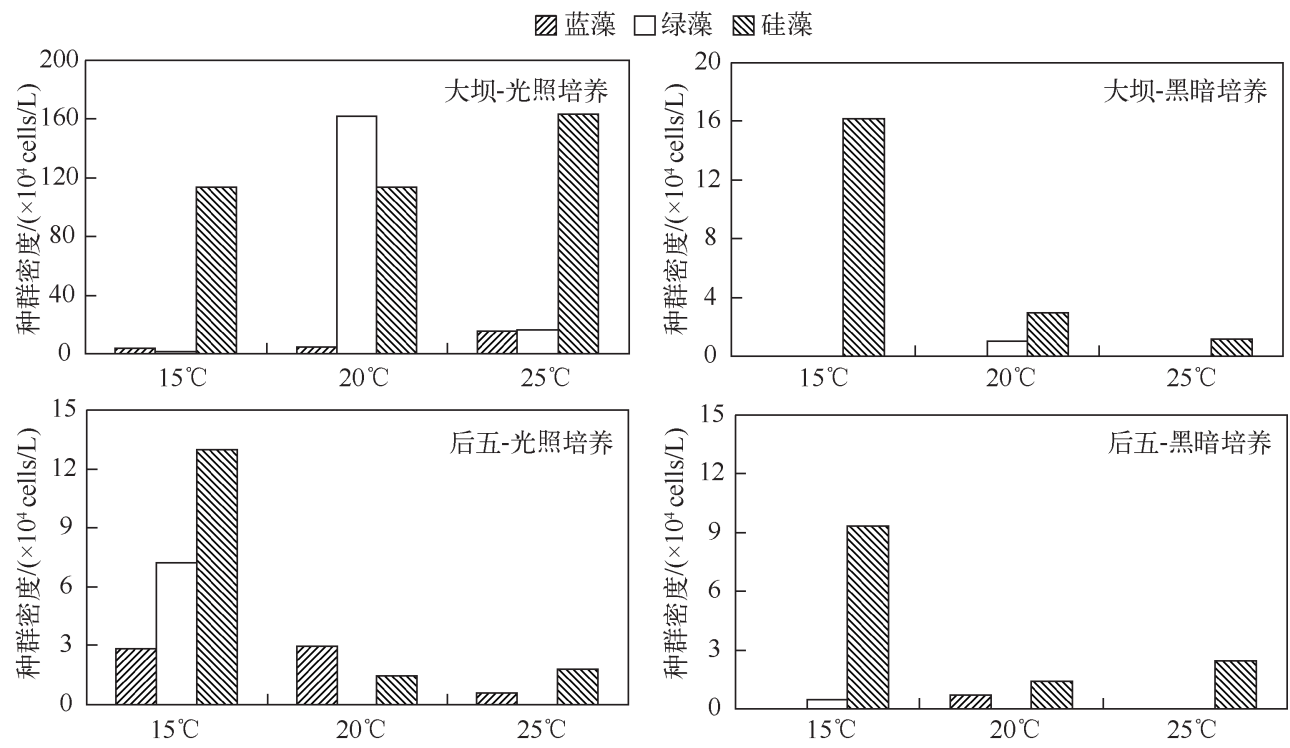

图 4 不同温度、光照条件下红枫湖不同湖区沉积物中藻类的复苏

Fig. 4 Recruitment of algae in sediments under different temperature and light conditions, Lake Hongfeng

除光照条件外,温度是影响藻类生长至关重要的因素 ${ }^{[2]}$. 在 $15^{\circ} \mathrm{C}$ 培养条件下后五沉积物中的越冬藻类已 恢复了相当的活性,培养基中藻类的种群密度已达到 $9.8 \times 10^{4}$ (黑暗培养) 和 $23.0 \times 10^{4}$ (光照培养) cells $/ \mathrm{L}$ (图 4). 在此基础上升温至 $20^{\circ} \mathrm{C}$ 继续培养一周后发现,蓝藻种群密度有所升高, 而硅藻和绿藻种群密度均明 显降低. 这与前人报道基本一致, 即蓝藻在 $11.5 \sim 15^{\circ} \mathrm{C}$ 开始复苏, 在 $18 \sim 20^{\circ} \mathrm{C}$ 达到复苏的最大量 ${ }^{[22,25-26]}$. 大 坝沉积物的培养结果略有不同, 无论在光照或者黑暗条件下, 硅藻的种群密度始终远高于绿藻和蓝藻. 这与 赋存在大坝沉积物中越冬藻类种群密度和组成有关. 大坝沉积物中越冬藻类的种群密度虽然高达 $46.5 \times$ $10^{4} \mathrm{cells} / \mathrm{g}$,但是基本不含蓝藻, 而硅藻数量占沉积物藻类总量的 $74.7 \%$.

\section{3 结论}

1) 红枫湖表层水体藻类种群密度蓝藻》绿藻 > 硅藻 >甲藻, 蓝藻为红枫湖优势门类. 藻类种群密度秋 季初期最大,其次是春季初期和夏季,具有明显的季节性演化特征. 越冬藻类以蓝藻为主,其次是硅藻和绿 藻,水深对水体中藻类的种群密度及组成没有显著影响.

2) 越冬藻类的种群密度在沉积物中的分布与沉积物污染程度有关, 污染严重的大坝沉积物越冬藻类的 种群密度远高于其他湖区. 模拟实验表明,水体中的光照条件对藻类的复苏和生长产生重要的影响,温度和 沉积物越冬藻类的种群密度与组成同样影响藻类的复苏.

\section{4 参考文献}

[ 1 ] Shapiro J. Blue-green algae: why they become dominant. Science, 1972, 179:382-384. 
[2 ] 孔繁翔,高 光.大型浅水富营养化湖泊中蓝藻水华形成机理的思考.生态学报,2005,25(3):589-595.

[ 3 ] Reynolds CS. Cyanobacterial water blooms. Adv Bot Res, 1987, 13:67-143.

[ 4 ] Annika SD, Lars AH. Effect of bioturbation on recruitment of algal cells from the seed bank of lake sediments. Limnology and Oceanography, 2002, 47 (6):1836-1843.

[ 5 ] 顾海峰, 蓝东兆, 方 琦等. 我国东南沿海亚历山大藻休眠孢囊的分布和萌发研究. 应用生态学报, 2003,14(7): 1147-1150.

[6] Reynolds CS, Rogers DA. Seasonal variations in the vertical distribution and buoyancy of Microcystis aeruginosa Kiitz. Emend Elenkin in Rostherne Mere, England. Hydrobiologia, 1976, 48:17-23.

[ 7 ] Fallon RD, Brock TD. Overwintering of Microcystis in Lake Mendota. Freshwater Biol, 1981, 11:217- 226.

[ 8 ] Takamura N, Yasuno M, Sugahara K. Overwintering of Microcystis aeruginosa Kiitz, in a shallow lake. J Plankton Res, $1984,6: 1019-1029$.

[ 9 ] Preston T, Stewart WDP, Reynolds CS. Bloom-forming cyanobacterium Microcystis aeruginosa overwinters on sediment surface. Nature, $1980,288: 365-367$.

[10] Boström B, Pettersson AK, Ahlgren I. Seasonal dynamics of a cyanobacteria-dominated microbial community in surface sediments of a shallow, eutrophic lake. Aquat Sci, 1989, 51:153-178.

[11] Tsujimura S, Tsukada H, Nakahara H et al. Seasonal variation of Microcystis populations in sediments of Lake Biwa, Japan. Hydrobiologia, 2000, 434:183-192.

[12] 阎 荣, 孔繁翔, 韩小波. 太湖底泥表层越冬藻类群落动态的荧光分析法初步研究. 湖泊科学, 2004, 16 (2): $163-168$.

[13 ] Hansson LA, Rudstam LG, Johnson TB et al. Patterns in algal recruitment from sediment to water in a dimictic, eutrophic lake. Can J Fish Aquat Sci, 1994, 51 :2825-2833.

[14] Head RM, Jones RI, Bailey AE. An assessment of the influence of recruitment from the sediment on the development of planktonic populations of cyanobacteria in a temperate mesotrohic lake. Freshwater Biol, 1999, 41 : 759-769.

[15] Brunberg AK, Blomqvist P. Recruitment of Microcystis from lake sediments: the importance of littoral inocula. J Phycol, $2003,39: 58-63$.

[16] Verspagen JMH, Snelder EOFM, Visser PM et al. Recruitment of benthic Microcystis (Cyanophyceae) to the water column : internal buoyancy changes or resuspension. J Phycol, 2004, 40:260-270.

[17] Qin BQ, Hu WP, Gao G et al. Driving mechanism of sediment resuspension and conceptual pattern of internal release in Taihu Lake. Chinese Science Bulletin, 2003, 48:1822-1831.

[18 ] Fan CX, Zhang L, Qin BQ et al. Estimation of dynamic release of phosphorus from suspended particles under wave in Lake Taihu. Science in China: Series D, 2003, 33:760-768.

[19] 王雨春, 朱 俊,马 梅等. 西南峡谷型湖泊的季节性分层与水质的突发性恶化. 湖泊科学, 2005,17(1):54-60.

[20 ] Zhang YL, Qin BQ, Chen WM et al. Analysis on distribution and variation of beam attenuation coefficient of Taihu Lake's water. Analysis in Water Science, 2003, 14:447-453.

[21] Hansson LA. Algal recruitment from lake sediments in relation to grazing, sinking, and dominance patterns in the phytoplankton community. Limnology and Oceanography, 1996, 41(6) :1312-1323.

[22] 李阔宇, 宋立荣, 万 能. 底泥中微囊藻复苏和生长特性的研究. 水生生物学报, 2004,28(2):113-118.

[23] 万国江, 万恩源, 陈敬安等. 深水人工湖环境生物地球化学过程研究: 以贵州红枫湖一一百花湖为例. 地球与环境, 2010,38 (3) :262-270.

[24] 陈敬安,张 维,张润宇等. 红枫湖底泥污染物空间分布特征. 见:第十三届国际湖泊大会论文集. 武汉,2009.

[25] 陶 益,孔繁翔,曹焕生等.太湖底泥水华蓝藻复苏的模拟. 湖泊科学, 2005,17(3):231-236.

[26] 曹焕生,孔繁翔,谭 啸等. 太湖水华蓝藻底泥中复苏和水柱中生长的比较. 湖泊科学,2006,18(6) :585-589.

[27] Lewis Jr WM. A revised classification of lakes based on mixing. Can J Fish Aquat Sci, 1983, 40:1779-1787.

[28] Tan X, Kong FX, Zhang M et al. Recruitment of phytoplankton from winter sediment of Lake Taihu: A laboratory simulation. Journal of Freshwater Ecology, 2009, 24(2):339-341.

[29] Barbiero RP, Kann J. The importance of benthic recruitment to the population development of Aphanizomenon flos-aquae and internal loading in a shallow lake. J Plankton Res, 1994, 16:1581-1588.

[30 ] Cao HS, Kong FX, Tan JK et al. Recruitment of total phytoplankton, chlorophytes and cyanobaeteria from lake sediments recorded by photosynthetic pigments in a large, shallow lake( Lake Taihu China). Internat Rev Hydrobiol, 2005, 90(4) : 347-357.

[31] Verspagen JMH, Snelder EOFM, Visser PM et al. Benthic-pelagic coupling in the population dynamics of the harmful cyanobaeterium Microcystis. Freshwat Biol, $2005,50: 854-867$. 